\title{
Do hormonal contraceptives influence asthma severity?
}

\author{
L. Forbes, D. Jarvis, P. Burney
}

\begin{abstract}
Do hormonal contraceptives influence asthma severity?. L. Forbes, D. Jarvis, P. Burney. (C) ERS Journals Ltd 1999.

ABSTRACT: There is some evidence that endogenous progesterone and oestrogen levels influence asthma severity in females, but little is known about the effects of hormonal contraceptives. This study aimed to describe how females with asthma perceived the effects of hormonal contraceptives on symptom severity, and to describe the association between asthma severity and current use of hormonal contraceptives.

A questionnaire was sent to 891 females with asthma aged 20-30 yrs recruited from general practice registers in South London, UK. It asked about perceptions of the effects of hormonal contraceptives on asthma severity, about current use of hormonal contraceptives, and included an asthma quality of life questionnaire as a measure of asthma severity.

About 6\% of respondents who had ever used hormonal contraceptives reported that these had influenced asthma severity, $\sim 4 \%$ reporting worsening and $2 \%$ an improvement. There were no significant differences in asthma quality of life score between females currently taking hormonal contraceptives and those not, between those taking combined and progesterone-only preparations, or between users of different progestagen types.

This study found no evidence of any important effect of hormonal contraceptives or their components on asthma severity in a group of females with relatively mild asthma.

Eur Respir J 1999; 14: 1028-1033.
\end{abstract}

Division of Public Health Sciences, Guy's, King's and St Thomas' School of Medicine, Capital House, 42 Weston Street, London SE1 3QD, UK.

\section{Correspondence: L. Forbes}

Division of Public Health Sciences

Guy's, King's and St Thomas' School of Medicine

Capital House

42 Weston Street

London SE1 3QD

UK

Fax: 4401714034602

\section{Keywords: Asthma}

asthma quality of life score

contraception

Received: October 281998

Accepted after revision July 181999

Endogenous oestrogen and progesterone level may have an effect on asthma severity in females. About a third of females with asthma report worse symptoms in the perimenstrual part of their cycle [1-4]. In a study in the USA, a higher proportion of asthmatic females was admitted to hospital in the perimenstrual part of the cycle than at other times [5]. Studies of objective measures of asthma severity over the menstrual cycle are less consistent. Three studies found no difference in bronchial hyperresponsiveness (BHR) at two different times of the menstrual cycle [6-8], though the subjects may not have been representative of all asthmatic females, the sample sizes were small, and the times of the menstrual cycle chosen for measurement of BHR may not have been those most likely to show differences. In one study of 9 females, however, BHR increased in the luteal phase [9]. Because of the inconsistency between these studies, firm conclusions cannot be drawn about the effect of endogenous hormones on asthma severity in females.

There is little published research on the effect of exogenous sex hormones on asthma and the results are also inconsistent. In the study by TAN et al. [9] the luteal phase increase in BHR was much smaller in 9 females taking oral contraceptive pills, suggesting a beneficial effect on asthma severity, though no differences in symptom outcomes were demonstrated. Some case reports and uncontrolled studies suggest that oestrogen or progesterone improve asthma symptoms or lung function [10-12] but others suggest that they might cause a deterioration [1315]. Females who had ever used hormone replacement therapy had a higher incidence of asthma in a large epidemiological study [16]. The association remained after controlling for other risk factors and held for oestrogenonly and combined preparations.

This study aimed to further explore the relation between use of hormonal contraceptives and asthma severity in order to inform decisions about prescribing hormonal contraceptives in asthma. The specific objectives were to describe how females with asthma perceived the effects of hormonal contraceptives on asthma symptoms and to describe the associations between asthma severity and: 1) current use of hormonal contraceptives; 2) current use of oestrogens; and 3) current use of different progestagen types.

\section{Methods}

Subjects were selected from general practice registers in South London, using computerized searches combining the following characteristics: female; aged 20-29 yrs inclusive on the 1 March 1997; and at least one prescription of inhaled $\beta$-agonists since 1 March 1995, that is, in the 2 yrs before the survey started.

A postal questionnaire survey of subjects was carried out. Nonresponders were remailed after 3 and 6 weeks. The questionnaire included the Asthma Quality of Life Questionnaire (AQLQ) as a measure of asthma severity [17]. This consists of 20 statements about asthma symptoms and how they have affected daily activities over the last month, answered on a 5-point Likert scale from "Not 
at all", to "Very severely", and scored $0-4$. The sum of scores (maximum 80 ) is divided by 8 to give a score out of 10; the higher the total score, the greater the influence of symptoms on daily activities.

The questionnaire also collected information on a number of other measures of asthma severity, including use of inhaled steroids, ownership of a nebulizer, admission to hospital in the previous 12 months, number of visits to the general practitioner in the last 6 months and numbers of days unable to work or carry out usual activities in the last 6 months.

Perceptions of the effects of hormonal contraceptives on asthma were elicited using the questions "Have any contraceptive pills made your asthma better?" and "Have any contraceptive pills made your asthma worse?" and the equivalent for injected contraceptives. Possible response categories were "Yes", "No" and "Don't know".

Questions were designed to ask about contraceptive use in the last month, which was considered to be current use.

Information was also collected about potential confounding factors: ethnic group, smoking, number of children under the age of 18 living at home, age at leaving full-time education, current use of inhaled steroids and use of nonsteroidal anti-inflammatory medication for perimenstrual symptoms. A Townsend Deprivation Score was obtained for each subject's electoral ward of residence using 1991 census data; the higher the score, the more deprived the ward of residence.

For sample size calculations it was assumed that the mean and standard deviation of the AQLQ score would be similar to that found in a study of asthmatic adults aged $20-44$ yrs in Greenwich, also in South London, UK [18]. A sample size of 500 was chosen to detect a difference of 5 points on the original 80-point scale between current users and non-users with $>90 \%$ power, assuming that $\sim 30 \%$ of subjects would be current users. Assuming that of current users $\sim 10 \%$ would be taking progesterone-only preparations, and $\sim 50 \%$ levonorgestrel and $\sim 25 \%$ third generation progestagens, this sample size was estimated to be sufficient to detect differences of 12 points on the 80 -point scale between users of progesterone-only and combined preparations, and of 9 points between users of levonorgestrel and third generation progestagens, both with $>80 \%$ power.

Ethical approval for the study was obtained from the St Thomas' Hospital Ethics Committee.

\section{Analysis}

Age was derived in responders from the difference between date of birth and date of response, and in nonresponders from the difference between date of birth and the median date of response. The age of responders and nonresponders was compared using a t-test and Townsend Deprivation Score using a Mann-Whitney U-test.

Females who responded "No" to the question "Have you ever had asthma?" were excluded from all subsequent analyses. The AQLQ score was calculated for all subjects responding to $\geq 11$ statements. For these, the sum of the scores for individual statements was divided by the number of responses given and multiplied by 20 . The AQLQ score was obtained by dividing the result by 8 . The square root of the AQLQ score is normally distributed [19] and was used for all analyses.

AQLQ score was compared in: 1) females currently taking hormonal contraceptives and those not; 2) females currently taking progesterone-only and combined contraceptives; and 3) females currently taking different progestagen types. The comparisons were carried out using multiple regression analyses to control for the effect of potential confounding variables. Associations between other indicators of asthma severity (use of inhaled steroids, ownership of a nebulizer, admission to hospital in the previous 12 months, visits to general practitioner in the last six months and days unable to work or carry out usual activities in the last 6 months) and use of hormonal contraceptives were also examined, using logistic regression to control for the effect of potential confounding variables. Data were analysed using the statistics package Stata 5.0 (STATA Corp., College Station, TX, USA).

\section{Results}

The questionnaire was mailed between March and December 1997 to 891 females registered with 24 general practices in South London, UK. After the mailing, 83 of the females were found to have moved home. Four hundred and eighty-one questionnaires were returned; $54 \%$ of the total mailed, and $60 \%$ of the 808 who were assumed to be resident at the address to which the questionnaire had been sent.

Age was available for all responders and $87 \%$ of nonresponders. Nonresponders for whom age was available were slightly older than responders (mean age of responders 25.7 yrs; nonresponders 26.1 yrs; $95 \%$ confidence intervals (CI) for the difference $-0.9--0.03 \mathrm{yrs}$ ). A Townsend Deprivation Score was available only for subjects for whom complete postcode was available: $87 \%$ of responders and $72 \%$ of nonresponders. There was no significant difference in the Townsend Deprivation Score between responders and nonresponders.

Twenty respondents are excluded from further analyses because they responded "No" to the question "Have you ever had asthma?". The definition of asthma in this study is, therefore, prescription of inhaled $\beta$-agonists in the previous 2 yrs and reporting ever having had asthma. Of the 457 subjects for whom an AQLQ score was considered calculable (>11 responses), 451 (99\%) gave responses to at least 19 of the 20 statements. Mean square root of the AQLQ score was $1.47,95 \%$ CI $1.42-1.52$. This is equivalent to, for example, answering "Mildly" to $\sim 17$ of the 20 statements, and "Not at all" to the remainder.

Figure 1 shows the subjects' ever and current exposure to hormonal contraceptives. One hundred and eighty two subjects $(39 \%)$ reported currently taking hormonal contraceptives. Characteristics of subjects taking hormonal contraceptives and those not are shown in table 1. There were no significant differences in age, Townsend Deprivation Score, ethnic group, current smoking, and age at leaving full-time education between the two groups.

Three hundred and eighty-nine subjects $(84 \%)$ reported that they had ever taken hormonal contraceptives, of whom $383(98 \%)$ had taken the oral contraceptive pill (OCP) and $54(14 \%)$ contraceptive injections. Only 22 subjects $(6 \%$ of ever users of any hormonal contraceptives) reported any 


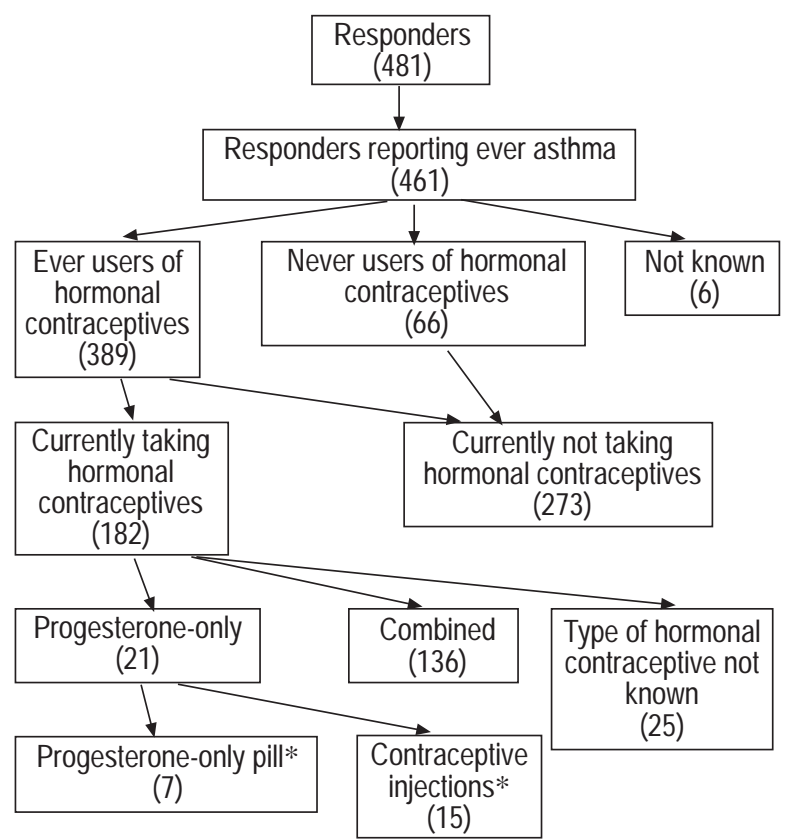

Fig. 1. - Subjects' exposure to hormonal contraceptives. *: One subject reported current use of both progesterone-only pill and contraceptive injections.

effects on asthma severity. Table 2 gives the numbers and proportions of subjects who reported improvement and worsening of asthma severity by type of contraceptive used and the AQLQ score in each group. Subjects responding "Yes" to either "Have any contraceptive pills made your asthma worse?" or "Have any contraceptive injections made your asthma worse?" had a higher AQLQ score, suggesting more severe asthma, than those responding "No" or "Don't know" (mean square root of AQLQ score 1.74 versus $1.47,95 \%$ CI of difference $0.01-0.53$ ). This difference is equivalent to a difference of $\sim 7$ points on the original 80 point scale. Subjects responding "Yes" to either "Have any contraceptive pills made your asthma better?" or "Have any contraceptive injections made your asthma better?" also had a higher AQLQ score that those who responded "No" or "Don't know", but the difference was smaller and not statistically significant.

The mean square root of the AQLQ score in subjects currently taking hormonal contraceptives was 1.43 (95\% CI 1.35-1.49) and in those not taking hormonal contraceptives 1.49 (95\% CI 1.43-1.56). This difference was not significant (difference in mean square root of AQLQ score $-0.07,95 \%$ CI $-0.17-0.03$ ). The difference remained similar after controlling for age, ethnic group, current smoking, age at leaving full-time education, number of children under 18 living at home, use of nonsteroidal anti-inflammatory agents, use of inhaled steroids and Townsend Deprivation Score (adjusted difference in mean square root of AQLQ score $-0.03,95 \%$ CI $-0.16-0.10$ ). Table 3 shows differences in AQLQ score by current hormonal contraceptive use and by potential confounding factors, after controlling for all the other variables shown on the table. Only use of inhaled corticosteroids remained a significant predictor of AQLQ score.

The analysis was repeated comparing AQLQ score in subjects currently taking hormonal contraceptives with the 66 subjects who had never taken hormonal contraceptives, in order to address the possible bias introduced if females with more severe asthma discontinue use of hormonal contraceptives having perceived a deleterious effect on severity. There was no clinically or statistically significant difference in AQLQ score between subjects currently taking hormonal contraceptives and subjects who had never taken them, either before or after controlling for potential confounding variables. The 206 ex-users of hormonal contraceptives had a higher AQLQ score, suggesting worse asthma than current users (mean square root of AQLQ score 1.53 versus $1.43,95 \%$ CI for the difference $0.01-$ 0.21 ). This difference represents a difference of only $\sim 2$ points on the original 80-point scale. Moreover, the difference was no longer statistically significant after controlling for potential confounding variables.

There were no associations demonstrated between other indicators of asthma severity (use of inhaled steroids,

Table 1. - Characteristics of subjects

\begin{tabular}{|c|c|c|c|c|}
\hline & \multirow[b]{2}{*}{$\begin{array}{l}\text { All subjects } \\
(\mathrm{n}=461)\end{array}$} & \multicolumn{2}{|c|}{ Current use of hormonal contraceptives } & \multirow[b]{2}{*}{$\mathrm{p}$-value of difference* } \\
\hline & & $\begin{array}{c}\text { Yes } \\
(\mathrm{n}=182)\end{array}$ & $\begin{array}{c}\text { No } \\
(n=273)\end{array}$ & \\
\hline Mean age in years $\pm \mathrm{SD}$ & $26 \pm 3$ & $26 \pm 3$ & $26 \pm 3$ & 0.26 \\
\hline Median TDS & $-2.35(-8.32-5.34)$ & $-2.96(-8.36-3.97)$ & $-1.15(-8.36-3.97)$ & 0.13 \\
\hline \multicolumn{5}{|l|}{ Ethnic group } \\
\hline White & $350(75.9)$ & $147(80.8)$ & $200(73.3)$ & \\
\hline Afro-Caribbean & $85(18.4)$ & $29(15.9)$ & $53(28.2)$ & \\
\hline Asian & $17(3.7)$ & $5(2.8)$ & $12(4.4)$ & 0.32 \\
\hline \multicolumn{5}{|l|}{ Current smoking } \\
\hline No & $258(56.0)$ & $98(53.9)$ & $156(57.1)$ & \\
\hline Yes & $202(43.8)$ & $84(46.2)$ & $116(42.5)$ & 0.46 \\
\hline \multicolumn{5}{|c|}{ Age left full-time education } \\
\hline Age $\leq 18$ & $198(42.5)$ & $86(47.3)$ & $112(41.0)$ & \\
\hline Age $\geq 19$ & $206(44.7)$ & $75(41.2)$ & $127(46.5)$ & 0.37 \\
\hline \multicolumn{5}{|c|}{ No. children $<18$ yrs living at home } \\
\hline 0 & $287(62.3)$ & $119(65.4)$ & $166(60.8)$ & \\
\hline 1 & $88(19.1)$ & $33(18.1)$ & $54(18.7)$ & \\
\hline$\geq 2$ & $71(15.4)$ & $25(13.7)$ & $45(16.5)$ & 0.59 \\
\hline
\end{tabular}

Data are presented with interquartile range or percentage in parentheses, as appropriate. ${ }^{*}$ : between current users and non-users of hormonal contraceptives. TDS: Townsend Deprivation Score. 
Table 2. - Responses to questions about perceptions of the effects of hormonal contraceptives on asthma severity

\begin{tabular}{|c|c|c|c|c|}
\hline \multicolumn{4}{|c|}{ Response to question } & \multirow{3}{*}{$\begin{array}{l}\text { Difference between square } \\
\text { root AQLQ score in those } \\
\text { responding "Yes" and those } \\
\text { responding "No" or } \\
\text { "Don't know" }\end{array}$} \\
\hline \multicolumn{2}{|r|}{ "Yes" } & \multicolumn{2}{|c|}{ "No or Don't know" } & \\
\hline $\mathrm{n}$ & $\begin{array}{c}\text { Mean square root } \\
\text { AQLQ score }\end{array}$ & $\mathrm{n}$ & $\begin{array}{c}\text { Mean square } \\
\text { root AQLQ score }\end{array}$ & \\
\hline
\end{tabular}

Of 383 subjects who had ever used contraceptive pills:

\begin{tabular}{|c|c|c|c|c|c|}
\hline $\begin{array}{l}\text { "Have any contraceptive pills } \\
\text { made your asthma worse? }\end{array}$ & $12(3.1)$ & $1.74(1.42-2.07)$ & $36(96.3)$ & $1.47(1.42-1.52)$ & $0.27(-0.02-0.57)$ \\
\hline $\begin{array}{l}\text { "Have any contraceptive pills } \\
\text { made your asthma better?" }\end{array}$ & $4(1.0)$ & $1.71(0.92-2.51)$ & $37(97.9)$ & $1.48(1.43-1.53)$ & $0.23(-0.27-0.74)$ \\
\hline \multicolumn{6}{|c|}{ Of 54 subjects who had ever used contraceptive injections: } \\
\hline $\begin{array}{l}\text { "Have any contraceptive injec- } \\
\text { tions made your asthma worse? }\end{array}$ & $5(9.3)$ & $1.84(1.32-2.36)$ & $4(88.9)$ & $1.67(1.52-1.82)$ & $0.17(-0.31-0.64)$ \\
\hline $\begin{array}{l}\text { "Have any contraceptive injec- } \\
\text { tions made your asthma better"? }\end{array}$ & $4(7.4)$ & $1.60(0.63-2.57)$ & $5(92.6)$ & $1.69(1.65-1.84)$ & $-0.09(-0.69-0.51)$ \\
\hline \multicolumn{6}{|c|}{ Of 389 subjects who had ever used any hormonal contraceptive: } \\
\hline $\begin{array}{l}\text { To either question about contra- } \\
\text { ceptives making asthma worse }\end{array}$ & $15(3.9)^{*}$ & $1.74(1.47-2.01)$ & $36(93.8)$ & $1.47(1.42-1.52)$ & $0.27(0.01-0.53)$ \\
\hline To either question about contra- & $8(2.1)$ & $1.67(1.27-2.06)$ & $37(96.1)$ & $1.48(1.42-1.53)$ & $0.19(-0.19-0.57)$ \\
\hline
\end{tabular}
ceptives making asthma better

Data are presented with $\mathrm{n}$ percentage in parentheses and 95\% confidence intervals in parentheses. *: two subjects reported that both contraceptive pills and injected contraceptives had made their asthma worse. AQLQ: Asthma Quality of Life Questionnaire.

ow-nership of a nebulizer, admission to hospital in the previous 12 months, visits to general practitioner in the last 6 months and days unable to work or carry out usual activities in the last 6 months) and current use of hormonal contraceptives.

There was no significant difference in AQLQ score between the 134 subjects taking combined OCPs (mean square root of AQLQ score 1.42, 95\% CI 1.33-1.50) and the 21 subjects taking progesterone-only preparations (mean square root of AQLQ score 1.40, 95\% CI 1.17-1.67).

There was no significant difference in AQLQ score between subjects taking different progestagen types. The mean square root of AQLQ score in those taking norethisterone was 1.37 (95\% CI 1.19-1.55), levonorgestrel 1.38 (95\% CI 1.27-1.49) and third generation progestagens 1.48 (95\% CI 1.31-1.64).

\section{Discussion}

Only a small proportion of females with asthma reported that hormonal contraceptives influenced the severity of their asthma. Females who reported that hormonal contraceptives had made their asthma worse had slightly more

Table 3. - Associations between Asthma Quality of Life Questionnaire (AQLQ) score and current hormonal contraceptive use and potential confounding variables

\begin{tabular}{|c|c|c|}
\hline Variable & & $\begin{array}{c}\text { Difference in square root } \\
\text { AQLQ score* }\end{array}$ \\
\hline $\begin{array}{l}\text { Use of hormonal contraceptives } \\
\text { Reference group: not currently taking hormonal } \\
\text { contraceptives }\end{array}$ & Currently taking hormonal contraceptives & $-0.03(-0.16-0.10)$ \\
\hline Age group & $24-27 \mathrm{yrs}$ & $0.00(-0.18-0.18)$ \\
\hline Reference group: $<24$ yrs & $\geq 28$ yrs & $0.02(-0.15-0.19)$ \\
\hline Number of children aged under 18 living at home & One & $0.03(-0.15-0.21)$ \\
\hline Reference group: none & Two or more & $0.09(-0.10-0.28)$ \\
\hline Ethnic group & Afro-Caribbean & $0.08(-0.09-0.25)$ \\
\hline Reference group: White & Asian & $-0.16(-0.48-0.17)$ \\
\hline $\begin{array}{l}\text { Use of NSAIDs for perimenstrual symptoms } \\
\text { Reference group: no reported use }\end{array}$ & Takes NSAIDs for perimenstrual symptoms & $0.13(-0.001-0.26)$ \\
\hline $\begin{array}{l}\text { Use of inhaled corticosteroids } \\
\text { Reference group: no reported use }\end{array}$ & Current use of inhaled corticosteroids & $0.34(0.18-0.49)$ \\
\hline $\begin{array}{l}\text { Smoking } \\
\text { Reference group: no current smoking }\end{array}$ & Current smoker & $0.10(-0.03-0.23)$ \\
\hline $\begin{array}{l}\text { Age of leaving full-time education } \\
\text { Reference group: age } \geq 19\end{array}$ & Age $\leq 18$ & $0.04(-0.11-0.18)$ \\
\hline Townsend Deprivation Score & 2nd quartile & $-0.006(-0.19-0.18)$ \\
\hline Reference group: 1st quartile (most deprived) & $\begin{array}{l}\text { 3rd quartile } \\
\text { 4th quartile (least deprived) }\end{array}$ & $\begin{array}{l}0.002(-0.19-0.19) \\
-0.04(-0.21-0.14)\end{array}$ \\
\hline
\end{tabular}

Data are presented with $95 \%$ confidence intervals in parentheses. *: after controlling for all other variables shown in the table. NSAIDs: nonsteroidal anti-inflammatory drugs. 
severe asthma. The difference was equivalent to a difference of 7 points on the original 80-point scale. This could mean, for example, the difference between responding "Moderately" to 12 questions and "Not at all" to the remainder, and responding "Moderately" to 8 or 9 questions and "Not at all" to the remainder. This may be a clinically significant difference. There was no association between asthma severity, as measured by the AQLQ, or other indicators of severity, and current hormonal contraceptive use, nor current use of different progestagen types, nor use of progesterone-only contraceptives rather than combined.

The results suggest that in the majority of females with relatively mild asthma, there is no important effect of hormonal contraceptives on asthma severity, but that in females with more severe asthma, exogenous oestrogens and progesterone may influence severity.

In this study the AQLQ score was used as a measure of asthma severity. The validity of this score has been tested on 1,200 subjects in Australia [17], which found a significant correlation between the score and number of asthma medications and weak, although nonsignificant, correlations with BHR and with per cent predicted forced expiratory volume in one second. Validity as a measure of change over 4 months has also been studied [19]. Change in score was correlated with change in another symptom score and in BHR. Associations with change in peak expiratory flow rate (PEFR) and with the Sickness Impact Profile, a generic measure of quality of life, were in the expected directions though weaker and not significant. In the current study AQLQ score was strongly associated with other indicators of severity of asthma (data not shown). It is believed that the AQLQ provides a valid summary measure of asthma severity and that the findings of this study are not due to the inability of the score to discriminate between different degrees of severity.

The absence of an association between asthma severity and use of hormonal contraceptives is unlikely to be due to inadequate power. Given the proportion of subjects who were currently taking hormonal contraceptives in this study, the power to detect a significant difference in AQLQ score between current users and non-users of hormonal contraceptives of 5 responses on the 80-point scale was $>90 \%$. The power to detect a difference in AQLQ score of 10 responses to the questionnaire was $87 \%$ between subjects taking progesterone-only and combined preparations and $93 \%$ between subjects taking levonorgestrel and third generation progestagens.

It is believed that the $60 \%$ response rate is unlikely to have led to a spurious lack of association between asthma severity and use of hormonal contraceptives. It was expected that females who had observed an association between asthma and hormonal contraceptives, and those with more severe asthma and taking hormonal contraceptives, would be more likely to respond, which would have biased the study towards a positive association between use of hormonal contraceptives and asthma severity. There is no reason to believe that the lack of association observed arose from nonresponse, because this would imply that such an association was present in nonresponders.

A bias could have arisen in the study if females with more severe asthma are more likely to discontinue use of hormonal contraceptives having experienced an exacerbation of symptoms. However, in the study there was no clinically or statistically significant difference in asthma severity between females who had never taken hormonal contraceptives, were currently taking hormonal contraceptives and previous users of hormonal contraceptives. Moreover, the proportion of subjects reporting effects of hormonal contraceptives on asthma severity was small. It is therefore believed therefore that this bias is unlikely to explain any of the findings.

In a study of 20 females who had taken OCPs and who were attending a hospital outpatient clinic for asthma, two reported an improvement and two a worsening of their asthma symptoms that they attributed to taking them [1]. This study, which, to the authors' knowledge, is the first to attempt to measure perceptions of the effects of hormonal contraceptives on asthma severity in a large group of females, found that $\sim 4 \%$ of subjects who had ever used hormonal contraceptives reported that they had made their asthma worse, and $\sim 2 \%$ better, which suggests much less marked effects. One possible explanation is that the community-based sample had, on average, relatively mild asthma. A sample recruited from an outpatient population may consist of females with more severe asthma, who may be more susceptible to the effects of exogenous sex hormones.

There are reports of six cases in the literature suggesting that exogenous sex hormones may have a therapeutic role in asthma $[10,11]$. However, there are two case reports which suggest that they may make asthma worse $[13,14]$. These reports, however, are all about females with severe, difficult to control, asthma. The current study suggests that females with relatively mild asthma do not experience any change in asthma symptom severity with hormonal contraceptives.

A study of 15 postmenopausal females with asthma showed a small fall in PEFR after starting oestrogen replacement therapy [15], but no change in symptom severity. In another study, 14 females of childbearing age with asthma were given a daily oestrogen supplement on days 23-28 of the menstrual cycle. Compared with a previous cycle with no exogenous hormone supplementation, the females demonstrated improved symptom scores and a reduced premenstrual fall in PEFR [12]. However neither of these studies included controls so it cannot be concluded that there was any causal association between exogenous hormones and any of the outcomes measured.

A small study has reported reduced cyclical variation in BHR and PEFR in females taking the OCP [9]. However, in the absence of demonstrated differences in symptom outcomes it cannot be concluded from this study that oral contraceptives have any therapeutic potential in asthma.

In conclusion, this study suggests that there is no important effect of hormonal contraceptives on asthma severity in females with relatively mild asthma. A cross-sectional study cannot provide conclusive evidence of no association, and a prospective controlled study measuring clinical outcomes after starting hormonal contraceptives would be necessary to confirm or refute the present findings. The results indicate that such a prospective study in females with relatively mild asthma would probably not be an appropriate use of research resources. However, hormonal contraceptives may influence symptoms in a small proportion of females with more severe asthma. This finding may merit further research. In the meantime, this study should reassure prescribers and public health practitioners 
that it is unlikely that hormonal contraceptives influence the respiratory health of the majority of females with asthma.

\begin{abstract}
Acknowledgements. The staff of the following general practices are thanked for help with recruiting subjects: S.M. Ahmed, Waldron Health Centre, New Cross; Albion Street Health Centre, Rotherhithe; Bellenden Road Group Practice, Peckham; Clapham Park Surgery, Clapham; Crown Dale Medical Centre, Norwood; Downham Way Surgery, Downham; Falmouth Road Group Practice, Elephant and Castle; Grantham Centre, Stockwell; Grove Medical Centre, Deptford; Hurley Clinic, Kennington; The Jenner Practice, Forest Hill; Lee Road Surgery, Blackheath; The Medical Centre, New Cross; New Surgery, Brixton; Palace Road Surgery, Streatham Hill; The Queen's Road Partnership, New Cross Gate; Sternhall Lane Surgery, Peckham; Streatham Common Group Practice, Streatham; The Surgery, Belmont Hill, Lewisham; The Surgery, The Gardens, Peckham Rye; Surrey Docks Health Centre, Rotherhithe; Sydenham Green Health Centre, Sydenham; Torridon Road Surgery, Catford; Valley Road Surgery, Streatham. J. Sandhu, Senior Information Officer, Lambeth Southwark and Lewisham Health Authority, is also thanked for providing Townsend Deprivation Scores.
\end{abstract}

\section{References}

1. Hanley SP. Asthma variation with menstruation. $B r J$ Dis Chest 1981; 75: 306-308.

2. Gibbs CJ, Coutts II, Lock R, Finnegan OC, White RJ. Premenstrual exacerbation of asthma. Thorax 1984; 39: 833-836.

3. Rees L. An aetiological study of premenstrual asthma. $J$ Psychosomat Res 1963; 7: 191-197.

4. Eliasson O, Scherzer HH, DeGraff AC. Morbidity in asthma in relation to the menstrual cycle. $J$ Allergy Clin Immunol 1986; 77: 87-94.

5. Skobeloff EM, Spivey WH, Silverman R, Eshin BA, Marchelroad F, Alessi TV. The effect of the menstrual cycle on asthma presentations in the emergency department. Ann Intern Med 1996; 156: 1837-1840.

6. Pauli BD, Reid RL, Munt PW, Wigle RD, Forket L.
Influence of the menstrual cycle on airway function in asthmatic and normal subjects. Am Rev Respir Dis 1989; 140: 358-362.

7. Weinmann GG, Zacur H, Fish JE. Absence of changes in airway responsiveness during the menstrual cycle. $J \mathrm{Al}$ lergy Clin Immunol 1987; 79: 634-638.

8. Juniper EF, Kline PA, Roberts RS, Hargreave FE, Daniel EE. Airway responsiveness to methacholine during the natural menstrual cycle and the effect of oral contraceptives. Am Rev Respir Dis 1987; 135: 1039-1042.

9. Tan KS, McFarlane LC, Lipworth BJ. Modulation of airway reactivity and peak flow variability in asthmatics receiving the oral contraceptive pill. Am J Respir Crit Care Med 1997; 155: 1273-1277.

10. Beynon HLC, Garbett ND, Barnes PJ. Severe premenstrual exacerbations of asthma: effect of intramuscular progesterone. Lancet 1988; 2: 370-372.

11. Chandler MH, Schuldheisz S, Phillips B, Muse KN. Premenstrual asthma: the effect of estrogen on symptoms, pulmonary function, and $\beta_{2}$-receptors. Pharmacotherapy 1997; 17: 224-234.

12. Myers JR, Sherman CB. Should supplemental estrogens be used as steroid sparing agents in asthmatic women? Chest 1994; 106: 318-319.

13. Collins LC, Peiris A. Bronchospasm secondary to replacement oestrogen therapy. Chest 1993; 104: 1300-1302.

14. Lieberman D, Kopernik G, Porath A, Lazer S, Helmer D. Subclinical worsening of bronchial asthma during estrogen replacement therapy in asthmatic postmenopausal women. Maturitas 1995; 21: 153-157.

15. Horan JD, Lederman JJ. Possible asthmogenic effect of oral contraceptives. Canad Med Ass J 1968; 99: 130-131.

16. Troisi RJ, Speizer FE, Willett WC, Trichopolous D, Rosner B. Menopause, postmenopausal estrogen preparations and the risk of adult onset asthma. Am J Respir Crit Care Med 1995; 152: 1183-1188.

17. Marks G, Dunn S, Woolcock A. A scale for the measurement of quality of life in adults with asthma. $J$ Clin Epidemiol 1992; 45: 461-472.

18. Marks GB, Burney PG, Premaratne UN, Simpson J, Webb J. Asthma in Greenwich, UK: impact of the disease and current management practices. Eur Respir J 1997; 10: 1224-1229.

19. Marks G, Dunn S, Woolcock A. An evaluation of an asthma quality of life questionnaire as a measure of change in adults with asthma. J Clin Epidemiol 1993; 46: $1103-1111$. 